\title{
Yoga and PTSD: Improving Emotion-Regulation
}

\author{
Jennifer Storch* and Jerrilyn Cambron \\ Biomedical Sciences, USA
}

Submission: February 01, 2018; Published: April 26, 2018

*Corresponding author: Jennifer Storch, Biomedical Sciences, Denver, CO, USA, Email: jstorchwriting@gmail.com

Abstract

This is a narrative review of quantitative and qualitative research to explore the impact of yoga on symptoms of post-traumatic stress disorder (PTSD). This narrative review presents a high-level overview of the beneficial properties derived by practicing yoga, the specific physiological challenges associated with PTSD, and the medically significant relationship between yoga and PTSD diagnosis and symptoms as evidenced by published medical studies.

Yoga practice is shown to improve emotion-regulation and decrease avoidance and emotional suppression. Yoga participants with post-traumatic stress disorder show an improved ability to manage intense emotions while remaining focused on the present moment. These enhanced capabilities reduce the conditioned fear response, which is considered a crucial development in eliminating post-traumatic stress disorder.

The focus of this review is primarily placed on a 10-week randomized control trial, 20 -week case-series, and two long-term follow-up studies. These qualitative and quantitative studies specifically evaluate the effects of trauma-sensitive yoga practice on treatment-resistant post-traumatic stress disorder. The three quantitative studies result in statistically significant outcomes and vary in treatment length. Special emphasis is placed on yoga practice frequency and duration in relation to the symptoms and diagnosis of treatment-resistant PTSD.

Given that traditional treatment models for post-traumatic stress disorder have high drop-out rates and can contribute to symptom worsening, the promising results shown by yoga treatment for complex post-traumatic stress disorder are particularly notable and worthy of further research.

Keywords: Post-traumatic stress disorder; Yoga; Mind-body therapy; Emotion-regulation; Stress; Complex trauma; Avoidance; Mindfulness; PTSD

\section{A Medical Overview of Yoga}

Yoga is defined as a "comprehensive system of practices for physical/psychological health and well-being [1]." Yoga has been researched as a primary and adjunctive treatment for a wide variety of medical disorders, including psychiatric conditions. Asthma, heart, disease, hypertension, diabetes, chronic pain, arthritis, and insomnia are effectively treated with yoga [2-9], as is a range of mental health problems.

Three integrative components constitute a hatha yoga practice: breathing exercises, physical postures, and meditation/ mindful attention to the present moment $[10,11]$. Each of these principal components affect neurobiological functioning [12]. Different styles of yoga emphasize the individual components to varying degrees. For the purposes of this paper, the focus is on a specific style of hatha yoga called kripalu.

In hatha yoga, physical postures emphasize flexibility over aerobic fitness; and attention is focused on sensory experiences: specifically, breathing and physical sensations [10]. Kripalu is a form of hatha yoga that specifically emphasizes the mind-body connection, nonjudgmental self-observation, and attention to the present moment [13]. Kripalu yoga, in conjunction with trauma-sensitive techniques, is often employed in post-trauma yoga interventions.

\section{Mind-body awareness}

Yoga is considered to be a mindfulness technique [14]. Mindbased therapies, like yoga, are shown to improve the ability to remain focused on present experiences [15-28]. The concept of mindfulness, or "nonjudgmental attention to experiences in the present" [13], is further described as the ability to approach experiences with curiosity, openness, and acceptance [29-31]. Enhanced mindfulness is associated with increased attention regulation, emotion regulation, and body awareness [29-31].

Practicing yoga is shown to aid the development of a heightened body awareness [10]. Body awareness is considered to be central to consciousness and emotional regulation [3235]. The ability to "know how one feels" depends on brain regions involved in registering internal homeostasis [36,33-51]. Enhanced awareness of the body can assist in observing the physiological aspects of physical sensations (e.g., quickening heartbeat, shallow breathing) [37-40]. Noticing these physiological cues can provide information about the internal 
environment of an individual, which is a required component for accurately identifying an emotional response [37-40].

Awareness of the transient nature of one's emotional experience may effectively change one's perspective of the self [38]. By enhancing mind-body awareness, practicing yoga may help individuals identify emotional responses and adjust cognitive processes and behaviors, as well as increase resilience [2]. Practicing yoga may also be an inherently satisfying activity and encourage behavioral activation of other pleasant activities [41].

\section{Trauma-sensitive yoga}

For traumatized individuals, the style of yoga is instrumentally important. Clinicians and trauma patients need to be aware of the significance in choosing a gentle style of yoga and an instructor who emphasizes openness to modifications and respects personal space [11]. Traumatized individuals should be prepared to process the challenging emotions and sensations that arise during yoga practice [11].

Trauma-sensitive yoga, in particular, involves guidelines that focus on safety, predictability, and nonjudgmental selfobservation [14]. Trauma sensitive (TCTSY) certified instructors create a welcoming, accepting atmosphere [42]. Invitational language, like "when you are ready," reminds participants of their control over bodily choices, including to maintain, modify, or break from postures [10]. Trauma-sensitive certified instructors provide ample modifications for physical postures [14], yet refrain from hands-on assistance and moving around the room [43].

In contrast to more vigorous or rigid forms of yoga, TCTSY instructors encourage participants to proceed through yoga positions at their own pace and incorporate choices that feel appropriate [11]. Simple poses are built upon over time to maintain predictability [14], allowing participants the opportunity to explore their own body experiences [44]. Selfinquiry and curiosity is promoted through key words, such as "notice" and "allow" [10]. Aspects of mindfulness are emphasized [14]. Participants are encouraged to observe thoughts and feeling without labeling them as positive or negative [14]. Specific posttraumatic stress disorder (PTSD) symptoms are not discussed in trauma-sensitive classes, although questions and feedback are encouraged before and after class [14].

\section{The Complexity of PTSD}

Post-traumatic stress disorder (PTSD) is a common and chronic condition that affects women over twice as often as men [15]. Trauma that takes place during a developmental period as interpersonal brutality or acute adversity is considered complex trauma [11]. This type of trauma deeply influences an individual's sense of self and inhibits the establishment of a fundamental sense of trust and security [45]. Recurrent trauma exposure is consistently linked to a wide array of symptoms: mood disturbances, anxious arousal, dissociative traits, and impulsive, aggressive, or self-injurious behaviors $[17,18,46]$.

Complex trauma exposure is also related to emotional flippancy, difficulties in affect- and impulse-regulation, diminished interoceptive awareness, somatic grievances, impaired attentional capacities, low self-perception, and problems in interpersonal relationships [47]. The core of these challenges is thought to be self-regulatory deficits [46]. Underlying mechanisms involve alterations in neural structures that register bodily states and changes in physical self-awareness $[32,48]$. Loss of affect regulation, emotional awareness, and body awareness are shown to be significantly involved in PTSD pathology $[32,48]$.

A range of comorbidities is linked to PTSD. Complex trauma survivors are highly likely to develop comorbid psychiatric and physical health problems, including depression, anxiety, substance abuse, obesity, heart disease, and chronic pain syndromes [13,39,49-53]. Additionally, a lifetime diagnosis of PTSD corresponds to a higher risk of suicide than those without PTSD [13].

\section{Current treatment models}

Current treatments for the disorder are based on pharmacologic and cognitive models (not interoceptive awareness and somatic regulation) [10]. Upon completing cognitive-behavioral treatment interventions, fewer than half of patients show clinically meaningful improvement [10,54]. The majority of people seeking PTSD treatment continue to show substantial residual symptoms after psychosocial treatments [54]. According to the Institute of Medicine, the scientific evidence currently available for traditional PTSD treatment lacks certainty [55].

Traditional treatment modalities (e.g., cognitive and exposure-based treatments) pose significant challenges for complex trauma survivors [19-24]. Forms of exposure treatment have been useful in treating PTSD, yet there is a high rate of incomplete response [10]. The low tolerance for traditional treatments is due to difficulties with affect- and impulseregulation [19-24]. High rates of treatment drop-out and worsening of symptoms are related to the sense of emotional "flooding" or dissociation interfering with the resolution of traumatic memories [19,25,48,56,57]. Complex trauma survivors "fluctuate between extremes of intrusive reliving of trauma symptoms in their bodies and minds, and conscious or unconscious avoidance of these overwhelming emotions, sensations and thoughts" $[11,58]$.

\section{Conditioned fear response and avoidance}

Avoidance is the most predictive symptom of PTSD severity and is shown to prolong and worsen PTSD symptoms [59-63]. Avoiding unpleasant internal experiences produces a narrow behavioral range called "psychological inflexibility" $[64,65]$. Psychological inflexibility is described as the inability to be mindful of the present $[64,65]$. 
Survivors of complex trauma have difficulty staying present in their lives and "tend to overreact to innocuous stimuli, under react to danger, and shut down in the face of challenges" $[11,48]$. A diminished awareness of bodily sensations, as well as a lack of perceived connection between external stimuli and inner reactions, is shown in individuals with PTSD [59-63].

Irrelevant or harmful reactions to new stimuli are caused by a conditioned fear response [66]. Eradicating this conditioned response requires the ability to manage intense emotions and maintain focused attention on stimuli, such as environmental or internal sensory input $[19,25,40,48]$. Effectively eliminating the conditioned fear response is considered crucial to resolving PTSD $[19,25,40,48]$.

\section{The Interaction Between Yoga and PTSD: A Qualitative Perspective}

Staying oriented in the present moment and managing powerful emotions are essential to the resolution of PTSD (and the conditioned fear response) [25]. Mindfulness techniques can improve emotion-regulation skills [30], counteract avoidance symptoms $[67,68]$ and enhance focused attention on the present moment. Yoga is hypothesized to be an effective modality for increasing mindfulness and, in turn, helping individuals with PTSD $[27,48,69]$.

Rhodes et al. [11] conducted long-term qualitative followup interviews with participants originally involved in a 10 -wk RCT by van Der Kolk et al. (2014), and who practiced yoga in the original RCT or after it ended [11]. A core phenomenon arose when evaluating the long-term healing experiences of yoga participants with treatment-resistant PTSD [11]. Overall, "a multidimensional process of claiming peaceful embodiment" was experienced by these yoga participants [11]. This phenomenon included an "improved connection with and sense of ownership and control over their bodies, emotions, and thoughts" [11].

Hermeneutic phenomenological analysis revealed a series of interconnected themes that further identify the core progression toward peaceful embodiment [11]. Significant overlap in the emotional experiences described by the participants may indicate the presence of potential patterns in the overall progression toward PTSD resolution. We can look to the participants' qualitative descriptions of the core phenomenon for insight into this post-trauma journey to recovery.

"I feel less like I have to put one face on for the outside world and that's not really who I am. I feel more authentic than I think I ever have. My not being able to get into my own skin was something that I did early on just to survive, and I just carried it forward. And now ... I can recognize I don't need to do that. It brings an appreciation that if you haven't been there you couldn't possibly imagine.... The okayness is from within [11]."

By increasing awareness and acceptance of emotions, the ability to tolerate unpleasant feelings and traumatic memories is improved [64]. Yoga participants "increasingly saw themselves in a new, more positive way with greater focus on their experiences in present-moment time and a growing sense of well-being in body and mind" [11]. Practicing distress tolerance in conjunction with a nonjudgmental attitude toward thoughts and experiences is shown to result in decreased avoidance or suppression of distressing emotions [13]. Participants continue to stay present instead of dissociating or avoiding, allowing them to begin desensitizing to painful or distressing interoceptive experiences [11].

“Because I was in the yoga class experiencing all different experiences -from nothing to something really scary and all different levels -it reminded me that I will have a lot of different experiences and that if I just wait long enough it will pass [11].”

Attending to the present moment-in spite of distress-may lead to increased acceptance, healthier emotion regulation strategies, and greater cognitive flexibility, thereby reducing PTSD symptoms [65]. Survivors gain a greater sense of control over their mind and body [11]. Emphasizing attention to thoughts, feelings, and emotions without judgment and focusing one's attention on the present moment can foster a greater tolerance for managing internal sensations and becoming more present-oriented [13].

"Being more gentle with myself and instead of -often when I had a symptom, not only would I be reacting to the trigger, but also judging myself for reacting to the trigger and thinking, I am an adult I should be over this by now and stuff like that. [The practice in yoga of] making your way slowly there and just being really gentle with yourself, whenever I am ready, that has helped me so that when I do feel triggered I feel like I can judge myself less, and be like alright, so this is how I feel right now and when I am ready to not feel that way anymore that will happen without pushing myself so hard [11]."

Yoga and other movement practices may stimulate meditative cognitive processes in a more approachable form than seated meditation [13,27]. Traumatized individuals show difficulty tolerating unstructured meditation [37]. Movement practices offer an enhanced sensory awareness and the opportunity to learn new skills, which provide a pivotal modality for focusing attention [13,27]. Guidance offered by an instructor during yoga practice helps maintain focus on bodily sensations and incorporate breathing exercises to modulate emotional arousal [37].

"The constant reminders to go at your own pace and to listen to your body for what it needs -when it's ready to turn or how far it wants to turn -that was super helpful and has extended in so many other places in my life. Yoga classes I have taken other places, I have heard people say, "You can push yourself; you don't realize what your body can do. Just push it." I feel like that's the kind of thing I have been doing my whole life. What is so valuable about this yoga class is that it was not about pushing yourself. It 
was about letting yourself get there in your own time [11]."

Even though survivors may find the heightened awareness of discomforting emotions or sensations to be difficult, yoga is shown to be a powerful practice for healing complex trauma symptoms [11]. Yoga may decrease hyperarousal symptoms and reduce the stress response through a down-regulation of the hypothalamic-pituitary-adrenal axis [26] and up-regulation of gamma-aminobutyric acid [70]. In both short- and longterm practice, yoga is associated with reduced basal cortisol and catecholamine secretion, as well as salutary effects on cognitive activity and cerebral neurophysiology [71,72]. Yoga practice is also linked to decreased sympathetic and increased parasympathetic activity [71,72].

"I think yoga's helped allowing there to be space between when something happens and my reaction. Because for a long time I didn't have the space to sort of make what I call a rational judgment, it was just based on sort of an emotional [reaction], or a habit. It's allowed me to pause and have that moment to say, okay well I don't have to react this way, or this person didn't mean it this way, and have that little bit of time to think about [my] reaction [11]."

Numerous associations between yoga and mental health indicators, such as "improved quality of life, emotional wellbeing, positive affect, stress management, self-concept, and body awareness and responsiveness," have been shown in studies [7376]. Yoga may also be effective for comorbid conditions such as depression and anxiety [77]. Yoga is a vastly different approach to treating trauma than traditional treatment modalities [11]. Yoga practice encourages participants to be accepting and aware of their emotions while remaining in the present moment, rather than focus on negative cognitive patterns and feared stimuli [11]. Offering yoga in clinical settings may be an attractive choice for patients who do not fully respond to traditional psychotherapy [78].

"Practicing yoga has given me hope. ... It's been a useful practice and tool to develop those things which led me to think I don't have to be that person that I always thought I was just destined to be, that I could actually change some things, and become the person that I've wanted to be. The trauma doesn't have to define me, although the trauma will always be part of me. I can change how I work, and how I want to be [11]."

Survivors that practiced yoga showed post-traumatic growth that extended beyond reducing symptoms, in which new meaning and appreciation was ascribed to their lives and selves [11]. A sense of personal strength and greater selfcompassion was cultivated amidst ongoing struggles associated with a traumatic past [11]. Yoga participants experienced newfound optimism about their future and a greater capacity for experiencing physical and emotional intimacy [11]. They began to believe they were deserving of healing and became hopeful to live in ways they wanted [11]
"I make conscious decisions now about my son, to raise him differently than how I was raised. So I can see that there are choices and options. You can be gentle in the world and [yoga] helps you see that. ... There are choices [11]."

\section{Quantitative Review of Yoga Intervention for PTSD}

For the purpose of this review, three separate studies are addressed with a focus on the quantitative results of the Clinician-Administered PTSD Scale (CAPS) in each study. It is important to note: the 10-week RCT and 20-week case-series examined the effects of trauma-sensitive yoga treatment (also called trauma-informed yoga) $[10,44]$. The long-term follow-up of the 10-wk RCT did not account for the type of yoga practiced post-study [66]. The participants in these studies were women with treatment-resistant, chronic PTSD who had previously attended at least three years of psychotherapy, with little alleviation from post-trauma symptoms $[10,44,66]$.

The first study is a 10-week randomized control trial (RCT) conducted by Van der Kolk et al. [10]. At the end of the trial, $52 \%$ of participants in the yoga treatment group no longer met criteria for PTSD, compared to the $21 \%$ in the control group [10]. The specifics of the trial can be found elsewhere [10]. The results of the trial concluded that the effects of yoga on PTSD diagnosis is statistically significant [10].

The second study is a 20 -week case-study of self-selected participants conducted by Price et al. [44]. This study was designed to examine the effectiveness of the same yoga treatment of the 10-week RCT with twice the number of sessions and highly-monitored yoga practice at home [44]. At the end of the case study, $83 \%$ of those who completed the treatment no longer met the criteria for PTSD (compared to $52 \%$ of the 10 -week RCT) $[10,44]$. The specifics of the study can be found elsewhere [44]. Participants showed significant reductions in PTSD symptoms and experienced a greater reduction overall than seen in similar treatments of shorter duration [44].

The third study is a long-term quantitative follow-up of the participants in the previously mentioned 10 -week RCT $[10,66]$. Regardless of the original treatment group (yoga or control), the majority of participants practiced yoga after completion of the 10-week trial [66]. In the follow-up study by Rhodes, et al [66], greater frequency of yoga practice was associated with greater decreases in PTSD symptoms and diagnosis

The regression analysis models in the long-term follow-up illustrate that the frequency of an individual's yoga practice is a significant predictor of change in CAPS [66]. Those who practiced yoga more frequently showed greater decreases in PTSD symptom severity and were less likely to meet the diagnostic criteria for PTSD [66]. The relationship suggests more frequent yoga practice significantly influences long-term outcomes of PTSD diagnosis and symptomology [66].

It is important to keep in mind the pronounced variability between these study types and the effect that may exert on 
drawing concrete conclusions when comparing across the studies. However, this research offers insight into the potential influence that frequent yoga practice may have on effectively reducing PTSD symptoms and diagnosis for individuals with treatment-resistant PTSD.

\section{Exploring the effects of frequency and duration}

When considering the results of the original 10-week RCT, van der Kolk suggested that the physical and interoceptive aspects of yoga were more critical to the change in CAPS than the social dimensions of the control group [10]. By the end of long-term follow-up, it also became clear that the frequency with which the participants practiced yoga had a significant effect on the change in CAPS over time [66].

The association between the frequency of yoga and PTSD symptoms is especially noteworthy given the significant distress levels of the participants [44]. Prior to engaging in yoga practice, many participants experienced little respite from the symptoms of PTSD [66], despite having a minimum of 3 years in psychotherapy with a focus on trauma $[44,66]$. Long-term yoga treatment may be linked to a better response from participants who have more severe PTSD symptoms [44]. Research shows positive physical and mental health outcomes are associated with longer yoga practice duration [79]. Extended periods of frequent yoga practice may lead to sustained decreases in PTSD symptoms [66].

Frequent yoga practice is positively correlated to both physical and mental health outcomes [79]. In a study of abuse survivors, self-concept was positively related to the frequency of yoga practice [73]. Yoga frequency is also positively associated with "positive psychological attitudes, relaxation, good health, vitality, and anti-inflammatory hormones" [44,79-81]. Stress, self-objectification, and inflammatory hormones (related to physical and mental health problems) are negatively associated with the frequency of yoga practice $[79,81,82]$. In a study on veterans, PTSD symptomatology was negatively associated with yoga practice frequency [26].

It is interesting to note in the follow-up study, after factoring in frequency of yoga practice, that participants who began in the control group and subsequently practiced yoga achieved better results than those who initially started in the yoga group [66]. The control treatment was a women's health education class that focused on active participation, support, and increasing knowledge of various health areas [10]. The specifics of the health education control treatment can be found elsewhere [10]. One possible explanation is there may be an added benefit of receiving women's health education in a group setting prior to practicing yoga frequently [66].

\section{Practical Recommendations}

Yoga is a popular activity among the general population [83]. As a treatment option, the accessibility and low-cost of yoga should not be underestimated [84]. Individuals with PTSD may be deterred from engaging in evidence-based therapies due to a fear of stigma associated with mental illness [85-88]. The group dynamic of a recurring yoga class within a community setting may also help foster social ties and establish positive interpersonal connections.

Yoga may offer trauma survivors an opportunity to reclaim wellness and peaceful healing that might otherwise be exceeding difficult to attain. The low certainty of traditional treatments for post-traumatic stress disorder is a problem plaguing PTSD patients and their loved ones. In a recent large clinical trial of prolonged exposure treatment, 59\% of subjects still had PTSD after 12 weeks of treatment, and $78 \%$ remained symptomatic at 6-month follow-up [89].

Given the low tolerance of cognitive and exposure-based treatments, new treatment models based on introspective awareness and somatic regulation need to be explored. Yoga poses a unique and compelling therapeutic option for this common and serious disorder [66]. The initial findings on the impact of trauma-sensitive yoga on PTSD symptoms are promising, yet the mechanisms that underlie the connection between yoga and positive mental health outcomes need to be further researched [44]. Additional studies are also needed to explore the effects of yoga on post-traumatic stress disorder in conjunction with other therapies, including health-education classes [66]. Further research is needed on the relationship between yoga practice frequency and dissociation, as well as between frequency of yoga practice and tension-reducing activities [66].

Additionally, further studies need to explore the potential physiological effects cultivated by practicing particular yoga poses over time. Certain yoga poses (asanas) may be more effective at producing specific physiological effects. An investigation of ancient yogic texts and Ayurvedic medicine may be warranted for further direction from historical findings and methods. The amount of yoga, or "dosage," needed to obtain desired results based on an individual's level of trauma severity is also a useful consideration for further studies [66]. Proactively addressing potential internal and external barriers [11] may help participants navigate the continuum nature of the healing process and maintain regular practice to achieve the maximal amount of therapeutic benefits.

\section{Summary}

In conclusion, trauma-sensitive yoga has shown to be an effective modality for reducing the symptoms and diagnosis of PTSD for treatment-resistant complex trauma survivors. By learning how to remain oriented in the present moment and focus nonjudgmental attention to internal sensations and perceptions, participants can improve their ability to observe connections between external stimuli and internal reactions. Managing intense emotions without dissociating or avoiding trauma-related thoughts and experiences can lead to positive emotional regulation and elimination of the conditioned fear response. 
No longer dominated by conditioned reactions, these individuals experience an increased sense of conscious space in which they can decide for themselves how to respond to environmental and internal input. Survivors are given a new sense of identity as they become capable of processing and experiencing life events in a healthy way. Given that these individuals participated in psychotherapy for at least three years with little change in PTSD symptoms or diagnosis, traumasensitive yoga offers a new way to reclaim peace and authenticity in their lives, as well as connect to others in a positive way.

Although it is challenging to face unpleasant emotions and inner sensations, these women were able to meet the haunting remnants of traumatic experiences in their mind and body. The bravery to remain in the present moment allowed them to overcome emotional suppression and outgrow their diagnosis. By committing themselves to the process of practicing yoga, they were able to face their terror and be still, which lead to a philosophically meaningful way of life.

\section{References}

1. Jindani FA, Khalsa G (2015) A Yoga intervention program for patients suffering from symptoms of posttraumatic stress disorder: a qualitative descriptive study. J Altern Complement Med 21(7): 401-408.

2. Khalsa SBS (2004) Yoga as a therapeutic intervention: a bibliometric analysis of published research studies. Indian J Physiol Pharmacol 48(3): 269-285

3. Becker I (2008) Uses of yoga in psychiatry and medicine. In: Muskin PR (Ed.), Complementary and Alternative Medicine and Psychiatry. American Psychiatric Press, Washington, DC, USA.

4. Grossman P, Niemann L, Schmidt S, Walach H (2004) Mindfulnessbased stress reduction and health benefits: a meta-analysis. J Psychosom Res 57(1): 35-43.

5. Sherman KJ, Cherkin DC, Erro J, Miglioretti D, Deyo R (2005) Comparing yoga, exercise, and a selfcare book for chronic low back pain: a randomized, controlled trial. Ann Intern Med 143(12): 849-856.

6. Sherman KJ, Cherkin DC, Connelly MT, Erro J, Savetsky J, et al. (2004) Complementary and alternative medical therapies for chronic low back pain: what treatments are patients willing to try? BMC Complement Altern Med 4(1): 9.

7. Williams KA, Petronis J, Smith D, Goodrich D, Wue J, et al. (2005) Effect of lyengar yoga therapy for chronic low back pain. Pain 115(1-2): 107117

8. Saper RB, Sherman KJ, Cullum Dugan D, Davis RB, Phillips RS, et al (2009) Yoga for chronic low back pain in a predominantly minority population: a pilot randomized controlled trial. Altern Ther Health Med 15(6): 18-27.

9. Carson JW, Carson KM, Porter LS, Keefe FJ, Shaw H, et al. (2007) Yoga for women with metastatic breast cancer: results from a pilot study. J Pain Symptom Manage 33(3): 331-341

10. Kolk BAVD, Stone L, West J, Rhodes A, Emerson D, et al. (2014) Yoga as an Adjunctive Treatment for Posttraumatic Stress Disorder. J Clin Psychiatry 75(6): e559-e565.

11. Rhodes AM (2015) Claiming peaceful embodiment through yoga in the aftermath of trauma. Complement Ther Clin Pract 21(4): 247-256.

12. Goodman L, Corcoran C, Turner K, Yuan N, Green B (1998) Assessing traumatic event exposure: general issues and preliminary findings for the stressful life events screening questionnaire. J Trauma Stress 11(3): 521-542.

13. Dick AM, Niles BL, Street AE, Dimartino DM, Mitchell KS (2014) Examining mechanisms of change in a yoga intervention for women: the influence of mindfulness, psychological flexibility, and emotion regulation on PTSD symptoms. J Clin Psychol 70(12): 1170-1182.

14. Mitchell KS, Dick AM, Dimartino DM, Smith BN, Niles B, et al. (2014) A Pilot study of a randomized controlled trial of Yoga as an Intervention for PTSD symptoms in women. J Trauma Stress 27(2): 121-128.

15. Kessler RC, Petukhova M, Sampson NA, Zaslavsky AM, Wittchen HU (2012) Twelve-month and lifetime prevalence and lifetime morbid risk of anxiety and mood disorders in the United States. Int J Methods Psychiatr Res 21(3): 169-184.

16. Van der Kolk BA (1994) The body keeps the score: memory and the emerging psychobiology of posttraumatic stress. Harv Rev Psychiatry 1(5): 253-265.

17. Pelcovitz D, van der Kolk BA, Roth S, Mandel F, Kaplan S, et al. (1997) Development of a criteria set and a structures interview for disorders of extreme stress. J Trauma Stress 10(1): 3-16.

18. Van der Kolk BA, Roth S, Pelcovitz D, Sunday S, Spinazzola J (2005) Disorders of extreme stress: the empirical foundation of a complex adaptation to trauma. J Trauma Stress 18(5): 389-399.

19. Ford JD, Kidd P (1998) Early childhood trauma and disorders of extreme stress as predictors of treatment outcome with chronic PTSD. J Trauma Stress 11(4): 743-761.

20. Ladwig KH, Marten Mittag B, Deisenhofer I, Hofmann B, Schapperer J (2002) Psychophysiological correlates of peritraumatic dissociative responses in survivors of life-threatening cardiac events. Psychopathology 35(4): 241-248.

21. McDonagh Coyle A, Friedman M, McHugo G, Ford JD, Sengupta A, et al. (2005) Randomized trial of cognitive-behavioral therapy for chronic post-traumatic stress disorder in adult female survivors of childhood sexual abuse. J Consult Clin Psychol 73(3): 515-524.

22. Michelson L, June K, Vives A, Testa S, Marchione N (1998) The role of trauma and dissociation in cognitive-behavioral psychotherapy outcome and maintenance for panic disorder with agoraphobia. Behav Res Ther 36(11): 1011-1050.

23. Tarrier N, Pilgrim H, Sommerfield C, Faragher B, Reynolds M, et al. (1999) A randomized trial of cognitive therapy and imaginal exposure in the treatment of chronic posttraumatic stress disorder. J Consult Clin Psychol 67(1): 13-18.

24.Zayfert C, Deviva JC, Becker CB, Pike JL, Gillock KL, et al. (2005) Exposure utilization and completion of cognitive behavioral therapy for PTSD in a "real world" clinical practice. J Trauma Stress 18(6): 637645.

25. Jaycox LH, Foa EB (1996) Obstacles in implementing exposure therapy for PTSD: case discussions and practical solutions. Clin Psychol Psychother 3(3): 176-184.

26. Ross A, Thomas S (2010) The health benefits of yoga and exercise: a review of comparison studies. J Altern Complement Med 16(1): 3-12.

27. Salmon P, Lush E, Jablonski M, Sephton SE (2009) Yoga and mindfulness: clinical aspects of an ancient mind/body practice. Cogn Behav Pract 16(1): 59-72.

28. Evans S, Tsao JCI, Sternlieb B, Zeltzer LK (2009) Using the biopsychosocial model to understand the health benefits of Yoga. J Complement Integr Med 6(1): 1-22.

29. Bishop SR, Lau M, Shapiro S, Carlson L, Anderson ND, et al. (2004) Mindfulness: A proposed operational definition. Clin Psychol Sci Prac 11(3): 230-241. 
30. Holzel BK, Carmody J, Vangel M, Congleton C, Yerramsetti, et al. (2011) Mindfulness practice leads to increases in regional brain gray matter density. Psychiatry Res 191(1): 36-43.

31. Kabat Zinn J (1990) Full catastrophe living: Using the wisdom of your mind to face stress, pain and illness. Dell, New York, USA.

32. Bluhm RL, Williamson PC, Osuch EA, Frewen PA, Stevens TK, et al. (2009) Alterations in default network connectivity in posttraumatic stress disorder related to early-life trauma. J Psychiatry Neurosci 34(3): 187-194

33. Critchley HD, Wiens S, Rotshtein P, Ohman A, Dolan RJ (2004) Neural systems supporting interoceptive awareness. Nat Neurosci 7(2): 189195

34. Craig AD (2013) Interoception: the sense of the physiological condition of the body. Curr Opin Neurobiol 13(4): 500-505.

35. Damasio AR (2003) Feelings of emotion and the self. Ann N Y Acad Sci 1001: 253-261.

36. Linehan MM, Armstrong HE, Suarez A, Allmon D, Heard HL (1991) Cognitive-behavioral treatment of chronically parasuicidal borderline patients. Arch Gen Psychiatry 48(12): 1060-1064.

37. Miller JJ, Fletcher K, Kabat Zinn J (1995) Three-year follow-up and clinical implications of a mindfulness meditation-based stress reduction intervention in the treatment of anxiety disorders. Gen Hosp Psychiatry 17(3): 192-200.

38. Hölzel BK, Lazar SW, Gard T, Schuman Olivier Z, Vago DR, et al. (2011) How does mindfulness meditation work? proposing mechanisms of action from a conceptual and neural perspective. Perspect Psychol Sci 6(6): 537-559.

39. Kessler RC, Sonnega A, Bromet E, Hughes M, Nelson CB (1995) Posttraumatic stress disorder in the National Comorbidity Survey. Arch Gen Psychiatry 52(12): 1048-1060.

40. Wilamowska ZA, Thompson Hollands J, Fairholme CP, Ellard KK, Farchione TJ, et al. (2010) Conceptual background, development, and preliminary data from the unified protocol for transdiagnostic treatment of emotional disorders. Depress Anxiety 27(10): 882-890.

41. Uebelacker LA, Tremont G, Epstein Lubow G, Gaudiano BA, Gillette T, et al. (2010) Open trial of Vinyasa yoga for persistently depressed individuals: Evidence of feasibility and acceptability. Behav Modif 34(3): 247-264

42. Emerson D, Sharma R, Chaudhry S, Turner J (2009) Yoga therapy in practice. Trauma-sensitive yoga: Principles, practice, and research. Int J Yoga Therap 19: 123-128.

43. Martin EC, Dick AM, Scioli Salter ER, Mitchell KS (2015) Impact of a yoga intervention on physical activity, self-efficacy, and motivation in women with PTSD symptoms. J Altern Complement. Med 21(6): 327 332

44. Price M, Spinazzola J, Musicaro R, Turner J, Suvak M, et al. (2017) Effectiveness of an extended yoga treatment for women with chronic posttraumatic stress disorder. J Altern Complement Med 23(4): 300309.

45. Courtois CA (2004) Complex trauma, complex reactions: assessment and treatment. Psychothr Res Pract Train 41(4): 412-425.

46. Cloitre M, Stolbach BC, Herman JL, van der Kolk B, Pynoos R, et al. (2009) Developmental approach to complex PTSD: childhood and adult cumulative trauma as predictors of symptom complexity. J Trauma Stress 22(5): 399-408.

47. Briere J, Spinazzola J (2005) Phenomenology and psychological assessment of complex posttraumatic states. J Trauma Stress 18(5): 401-412.
48. Van der Kolk BA (2006) Clinical implications of neuroscience research in PTSD. Ann N Y Acad Sci 1071(1): 277-293.

49. Chapman DP, Anda RF, Felitti J, Dube SR, Edwards VJ, et al. (2004) Adverse childhood experiences and the risk of depressive disorders in adulthood. J Affect Disord 82(2): 217-225.

50. Corso PS, Edwards VJ, Fang X, Mercy JA (2008) Health-related quality of life among adults who experienced maltreatment during childhood. Am J Public Health 98(6): 1094-1100.

51. Edwards VJ, Holden GW, Felitti VJ, Anda RF (2003) Relationship between multiple forms of childhood maltreatment and adult mental health in community respondents: results from the adverse childhood experiences study. Am J Psychiatry 160(8): 1453-1460.

52. Felitti VJ, Anda RF, Nordenberg D, Williamson DF, Spitz AM, et al. (1998) Relationship of childhood abuse and household dysfunction to many of the leading causes of death in adults: the Adverse Childhood Experiences (ACE) Study. Am J Prev Med 14(4): 245-258.

53. Walker EA, Unutzer J, Rutter C, Gelfand A, Saunders K, et al. (1999) Costs of health care use by women HMO members with a history of childhood abuse and neglect. Arch Gen Psychiatry 56(7): 609-613.

54. Bradley R, Greene J, Russ E, Dutra L, Westen D (2005) A multidimensional meta-analysis of psychotherapy for PTSD. Am J Psychiatry 162(2): 214-227.

55. Institute of Medicine (2008) Treatment of posttraumatic stress disorder: an assessment of the evidence committee on treatment of posttraumatic stress disorder. The National Academies Press, Washington DC, USA.

56. Beitchman JH, Zucker KJ, Hood JE, Dacosta GA, Akman D, et al. (1992) A review of the long-term effects of child sexual abuse. Child Abuse Negl 16(1): 101-118.

57. Pitman RK, Altman B, Greenwald E, Longpre RE, Macklin ML, et al. (1991) Psychiatric complications during flooding therapy for posttraumatic stress disorder. J Clin Psychiatry 52(1): 17-20.

58. Herman J (1997) Trauma and Recovery: the Aftermath of Violence from Domestic Abuse to Political Terror. Basic Books, New York, USA.

59. Marshal RD, Turner JB, Lewis Fernandez R, Koenan K, Neria Y, et al. (2006) Symptom patterns associated with chronic PTSD in male veterans: New findings from the National Vietnam Veterans Readjustment Study. J Nerv Ment Dis 194(4): 275-278.

60. Marx BP, Sloan DM (2005) Peritraumatic dissociation and experiential avoidance as predictors of posttraumatic stress symptomatology. Behav Res Ther 43(5): 569-583.

61. Palm KM, Follette VM (2011) The roles of cognitive flexibility and experiential avoidance in explaining psychological distress in survivors of interpersonal victimization. J Psychopathol Behav Assess 33(1): 7986.

62. Polusny MA, Follette VF (1995) Long-term correlates of child sexual abuse: Theory and review of the empirical literature. Appl Prev Psychol 4(3): 143-166.

63. Rosenthal MZ, Rasmussen Hall ML, Palm KM, Batten SV, Follette V (2005) Chronic avoidance helps explain the relationship between severity of childhood sexual abuse and psychological distress in adulthood. J Child Sex Abus 14(4): 25-41.

64. Follette V, Palm KM, Pearson AN (2006) Mindfulness and trauma: Implications for treatment. J Ration Emot Cogn Behav Ther 24(1): 4561.

65. Follette VM, Palm KM, Rasmussen Hall M (2004) Acceptance, mindfulness and trauma. In: Hayes SC, Follette VM, Linehan MM (Eds.), Mindfulness and acceptance: Expanding the cognitive behavioral tradition. Guilford Press, New York, USA. 


\section{Journal of Yoga and Physiotherapy}

66. Rhodes A, Spinazzola J, Kolk BVD (2016) Yoga for Adult Women with Chronic PTSD: A Long-Term Follow-Up Study. J Altern Complement Med 22(3): 189-196.

67. Emerson D, Sharma R, Chaudhry S, Turner J (2009) Trauma-sensitive yoga: Principles, practice, and research. Int J Yoga Therap 19: 123-128.

68. Thompson BL, Waltz J (2010) Mindfulness and experiential avoidance as predictors of posttraumatic stress disorder avoidance symptom severity. J Anxiety Disord 24(4): 409-415.

69. Shelov DV, Suchday S, Friedberg JP (2009) A pilot study measuring the impact of yoga on the trait of mindfulness. Behav Cogn Psychother 37(5): 595-598

70. Streeter CD, Jensen JE, Perlmutter RM, Cabral HJ, Tian H, et al. (2007) Yoga asana sessions increase brain GABA levels: A pilot study. J Altern Complement Med 13(4): 419-426.

71. Rocha KK, Ribeiro AM, Rocha KC, Sousa MB, Albuquerque FS, et al. (2012) Improvement in physiological and psychological parameters after 6 months of yoga practice. Conscious Cogn 21(2): 843-850.

72. West J, Otte C, Geher K, Johnson J, Mohr DC (2004) Effects of hatha yoga and African dance on perceived stress, affect, and salivary cortisol. Ann Behav Med 28(2): 114-118

73. Dale LP, Carroll LE, Galen GC, Schein R, Bliss A, et al. (2011) Yoga practice may buffer the deleterious effects of abuse on women's selfconcept and dysfunctional coping. J Aggress Maltreatment Trauma 20(1): 90-102.

74. Granath J, Ingvarsson S, von Thiele U, Lundberg U (2006) Stress management: a randomized study of cognitive behavioural therapy and yoga. Cogn Behav Ther 35(1): 3-10.

75. Impett EA, Daubenmier JJ, Hirschman AL (2006) Minding the body: yoga, embodiment, and well-being. Sex Res Soc Policy 3(4): 39-48

76. Moadel AB, Shah C, Wylie Rosett J, Harris MS, Patel SR, et al. (2007) Randomized controlled trial of yoga among a multiethnic sample of breast cancer patients: effects on quality of life. J Clin Oncol 25(28) 4387-4395.

77. Iverson KM, Hendricks AM, Kimerling R, Krengel M, Meterko M, et al. (2011) Psychiatric diagnoses and neurobehavioral symptom severity among OEF/OIF VA patients with deployment-related traumatic brain injury: A gender comparison. Womens Health Issues 21(4 Suppl): S210-S217.
78. Institute of Medicine (2012) Treatment for posttraumatic stress disorder in military and veteran populations: Initial assessment. National Academies Press, Washington, DC, USA

79. Kiecolt Glaser JK, Christian LM, Andridge R, Hwang BS, Malarkey WB, et al. (2012) Adiponectin, leptin, and yoga practice. Physiol Behav 107(5): 809-813.

80. Ross A, Friedmann E, Bevans M, Thomas S (2012) Frequency of yoga practice predicts health: Results of a national survey of yoga practitioners. Evid Based Complement Alternat Med 2012: 1-10.

81. Rice Cucci L, Williams JS (2001) Practice variables as predictors of stress and relaxation dispositions for yoga and meditation. Adv ABC Relax Appl Invent pp. 193-196.

82. Daubenmier JJ (2005) The relationship of yoga, body awareness, and body responsiveness to self-objectification and disordered eating. Psychol Women Q 29: 207-219.

83. Birdee GS, Legedza AT, Saper RB, Bertisch SM, Eisenberg DM, et al. (2008) Characteristics of yoga users: results of a national survey. J Gen Intern Med 23(10): 1653-1658.

84. Barnes PM, Powell Griner E, McFann K, Nahin RL (2004) Complementary and alternative medicine use among adults: United States, 2002. Advance Data (343): 1-19.

85. Hoge CW, Castro CA, Messer SC, McGurk D, Cotting DI, Koffman RL (2004) Combat duty in Iraq and Afghanistan, mental health problems, and barriers to care. N Engl J Med 351(1): 13-22.

86. Ouimette P, Vogt D, Wade M, Tirone V, Greenbaum M, et al. (2011) Perceived barriers to care among veterans health administration patients with posttraumatic stress disorder. Psychol Serv 8(3): 212223.

87. Wisco BE, Marx BP, Keane TM (2012) Screening, diagnosis, and treatment of post-traumatic stress disorder. Mil Med 177(8 Suppl): 7-13.

88. Reddy S, Dick AM, Gerber MR, Mitchell K (2014) The Effect of a yoga intervention on alcohol and drug abuse risk in veteran and civilian women with posttraumatic stress disorder. J Altern Complement Med 20(10): 750-756

89. Schnurr PP, Friedman MJ, Engel CC, Foa EB, Shea MT, et al. (2007) Cognitive behavioral therapy for posttraumatic stress disorder in women: a randomized controlled trial. JAMA 297(8): 820-830.

Your next submission with Juniper Publishers
will reach you the below assets
- Quality Editorial service
- Swift Peer Review
- Reprints availability
- E-prints Service
- Manuscript Podcast for convenient understanding
- Global attainment for your research
- Manuscript accessibility in different formats
( Pdf, E-pub, Full Text, Audio)
- Unceasing customer service
Track the below URL for one-step submission
https://juniperpublishers.com/online-submission.php

